\title{
Ionospheric and geomagnetic responses to changes in IMF $B_{Z}$ : a superposed epoch study
}

\author{
C. J. Davis ${ }^{1}$, M. N. Wild ${ }^{1}$, M. Lockwood ${ }^{1}$, Y. K. Tulunay ${ }^{2}$ \\ ${ }^{1}$ Rutherford Appleton Laboratory, Chilton, Didcot, OX11 OQX, United Kingdom \\ 2 Ortadoğu Teknik Üniversitesi, Havacilik, Mühendisliuği Bölümü, Ankara, Turkey
}

Received: 5 January 1996 / Revised: 23 July 1996 / Accepted: 30 July 1996

\begin{abstract}
Superposed epoch studies have been carried out in order to determine the ionospheric response at mid-latitudes to southward turnings of the interplanetary magnetic field (IMF). This is compared with the geomagnetic response, as seen in the indices $K_{p}, A E$ and Dst. The solar wind, IMF and geomagnetic data used were hourly averages from the years 1967-1989 and thus cover a full 22-year cycle in the solar magnetic field. These data were divided into subsets, determined by the magnitudes of the southward turnings and the concomitant increase in solar wind pressure. The superposed epoch studies were carried out using the time of the southward turning as time zero. The response of the mid-latitude ionosphere is studied by looking at the F-layer critical frequencies, $f_{\mathrm{o}} F 2$, from hourly soundings by the Slough ionosonde and their deviation from the monthly median values, $\delta f_{\mathrm{o}} F 2$. For the southward turnings with a change in $B_{z}$ of $\delta B_{z}>11.5 \mathrm{nT}$ accompanied by a solar wind dynamic pressure $P$ exceeding $5 \mathrm{nPa}$, the $\mathrm{F}$ region critical frequency, $f_{\mathrm{o}} F 2$, shows a marked decrease, reaching a minimum value about $20 \mathrm{~h}$ after the southward turning. This recovers to pre-event values over the subsequent $24 \mathrm{~h}$, on average. The Dst index shows the classic storm-time decrease to about $-60 \mathrm{nT}$. Four days later, the index has still to fully recover and is at about $-25 \mathrm{nT}$. Both the $K_{p}$ and $A E$ indices show rises before the southward turnings, when the IMF is strongly northward but the solar wind dynamic pressure is enhanced. The average $A E$ index does register a clear isolated pulse (averaging $650 \mathrm{nT}$ for $2 \mathrm{~h}$, compared with a background peak level of near $450 \mathrm{nT}$ at these times) showing enhanced energy deposition at high latitudes in substorms but, like $K_{p}$, remains somewhat enhanced for several days, even after the average IMF has returned to zero after 1 day. This $A E$ background decays away over several days as the $D s t$ index recovers, indicating that there is some contamination of the currents observed at the $A E$ stations by the continuing enhanced equatorial ring current. For data averaged over all seasons, the critical frequencies are depressed at Slough by $1.3 \mathrm{MHz}$, which is close to the lower decile of the overall distribution of $\delta f_{\mathrm{o}} F 2$ values. Taking 30 -day periods around summer
\end{abstract}

and winter solstice, the largest depression is 1.6 and $1.2 \mathrm{MHz}$, respectively. This seasonal dependence is confirmed by a similar study for a Southern Hemisphere station, Argentine Island, giving peak depressions of $1.8 \mathrm{MHz}$ and $0.5 \mathrm{MHz}$ for summer and winter. For the subset of turnings where $\delta B_{z}>11.5 \mathrm{nT}$ and $\mathrm{P} \leq 5 \mathrm{nPa}$, the response of the geomagnetic indices is similar but smaller, while the change in $\delta f_{\mathrm{o}} F 2$ has all but disappeared. This confirms that the energy deposited at high latitudes, which leads to the geomagnetic and ionospheric disturbances following a southward turning of the IMF, increases with the energy density (dynamic pressure) of the solar wind flow. The magnitude of all responses are shown to depend on $\delta B_{z}$. At Slough, the peak depression always occurs when Slough rotates into the noon sector. The largest ionospheric response is for southward turnings seen between 15-21 UT.

\section{Introduction}

The daily variation of the $F$ region electron density distribution greatly affects the propagation of radio waves through the ionosphere. Radio waves that are most affected lie in the frequency range $3 \mathrm{KHz}-30 \mathrm{MHz}$, where the extremes of this range correspond to signals in the Very Low Frequency (VLF) and High Frequency (HF) bands, respectively. Of particular importance is the maximum plasma density of the $F$ layer. A radio wave incident vertically on this layer will be reflected if its frequency is less than the critical frequency of the layer, $f_{\mathrm{o}} F 2$. This critical frequency (in $\mathrm{Hz}$ ) is numerically equal to about nine times the square root of the maximum electron density (in $\mathrm{m}^{-3}$ ). The maximum usable frequency, or MUF, of an oblique propagation path is roughly proportional to $f_{\mathrm{o}} F 2$, the ratio being known as the M-factor (e.g. Lockwood, 1983). The day-to-day variability of $f_{\mathrm{o}} F 2$ is the major problem in predicting MUFs and, despite many attempts to find the cause of this behaviour (e.g. Aravindan and Iver, 1990), its 
origins remain unknown. More major disturbances, or storms, are better documented but not much better understood, being the subject of a vast number of publications (e.g. Prölss et al., 1991 and references therein). This variability greatly limits the efficiency of systems using HF frequencies such as communications, radar and navigation (e.g. Bradley, 1991). An example of a storm-type variation of ionospheric densities is shown in Fig. 1. In this figure, the crosses show the hourly values of $f_{\mathrm{o}} F 2$ from Slough on 6-12 November, 1991. The circles show the monthly median values of $f_{\mathrm{o}} F 2$ at the same UT (i.e. the value that is exceeded on half the days in the month at the UT in question). The median values reveal the diurnal cycle of $f_{\mathrm{o}} F 2$, with larger values in the day (peaking in the early afternoon at about $12 \mathrm{MHz}$ ) and low values at night (falling to near $3 \mathrm{MHz}$ just before sunrise). A storm commences shortly before midnight on 8th November (day 2). Prior to this there are some quiet days, on which plasma densities are higher than the monthly median values. (The monthly medians tend to be depressed by the presence of storm-type depletions within the month, Wrenn et al., 1987). For several hours after the onset of the storm $f_{\mathrm{o}} F 2$ is either too low to be measured (sometimes because it is lower than $f_{o} E$ ) or the F-layer cannot be seen because of enhanced absorption of the sounding waves in the $\mathrm{D}$ region. However, $f_{\mathrm{o}} F 2$ recovers at sunrise on day 3, but is much lower than the monthly median on this day. By day 5 , the variation is almost exactly the same as the monthly median and by day 6 , it is almost back to the quiet day variation before the storm.

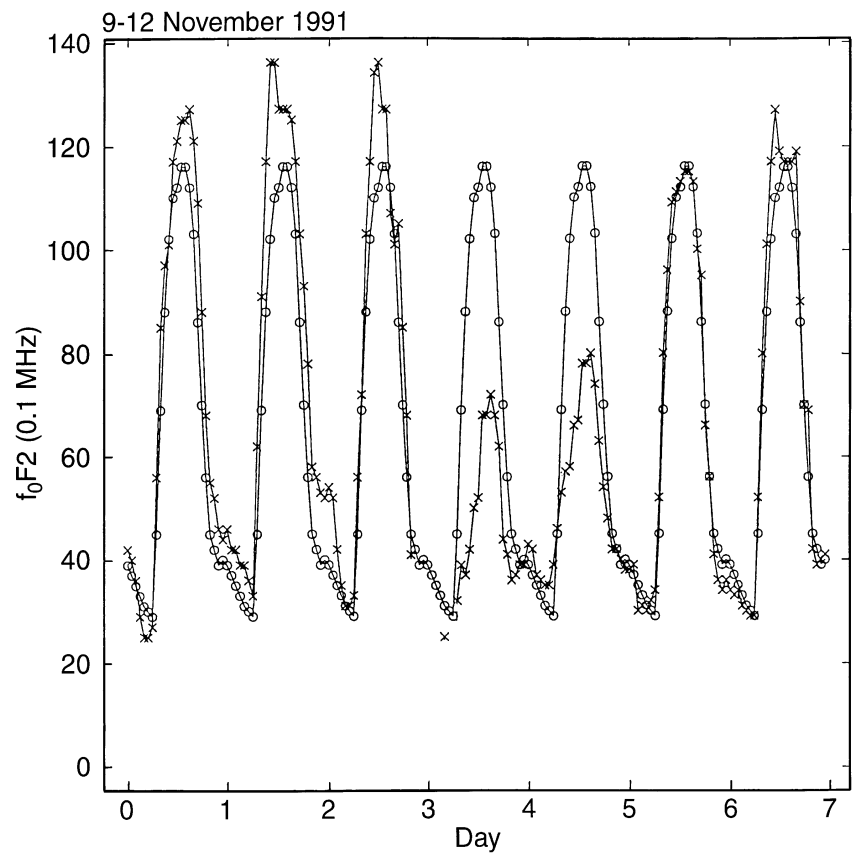

Fig. 1. A typical storm-time behaviour of F2 layer critical frequency, $f_{\mathrm{o}} F 2$, observed at Slough. The crosses are the hourly values observed on 6-12 November 1991, the open circles show the diurnal variation of the monthly median values. The former minus the latter is here termed $\delta f_{\mathrm{o}} F 2$
The storm-time behaviour is often quantified by taking the deviation of $f_{\mathrm{o}} F 2$ from its monthly median values in Fig. 1, i.e. the value of $f_{\mathrm{o}} F 2$ minus its monthly median value at that $\mathrm{UT}, \delta f_{\mathrm{o}} F 2$. This has largest negative values $\left(\delta f_{\mathrm{o}} F 2 \approx-5 \mathrm{MHz}\right)$ around noon on day 3 , but only very small negative values during the subsequent night when $f_{\mathrm{o}} F 2$ is small even on quiet days. A second, smaller minimum in $\delta f_{\mathrm{o}} F 2(\approx-4 \mathrm{MHz})$ is seen around noon on day 4 , whereas $\delta f_{\mathrm{o}} F 2$ is very close to zero throughout day 5 . Figure 2 places these values in context of the overall ionospheric variability. This is a plot of the distribution of all $\delta f_{\mathrm{o}} F 2$ values in the period of this survey (1967-1989), showing the number of occurrences of $\delta f_{\mathrm{o}} F 2$ in $0.1 \mathrm{MHz}$ bins. The dashed line is the probability distribution (i.e. the probability of a given $\delta f_{\mathrm{o}} F 2$ value) and the solid line is the cumulative probability distribution (here meaning the probability that $\delta f_{\mathrm{o}} F 2$ is larger than a given value). It can be seen that a depression of as large as $\delta f_{\mathrm{o}} F 2=-5 \mathrm{MHz}$ (as in Fig. 1) is very rare indeed ( $<0.1 \%$ of all soundings). The distribution is not symmetric, such that negative $\delta f_{\mathrm{o}} F 2$ values (depletions) are slightly more common than positive $\delta f_{\mathrm{o}} F 2$ (enhancements) of the same magnitude. As a result most $\delta f_{\mathrm{o}} F 2$ lie in the range $-4 \mathrm{MHz}$ to $+3 \mathrm{MHz}$. A large number of cases show $\delta f_{\mathrm{o}} F 2=0$, most of which are for night conditions. Note that other papers have discussed $\delta f_{\mathrm{o}} F 2$ as a ratio of the median value or the actual $f_{\mathrm{o}} F 2$ values as a ratio of the median (e.g. Wu and Wilkinson, 1995) as they will not show as large a diurnal variation as $\delta f_{\mathrm{o}} F 2$. However, there is no guarantee that any one ratio will completely remove the diurnal variation and we prefer to work with the absolute deviation from the median and bear in mind that it will show a strong diurnal variation. One

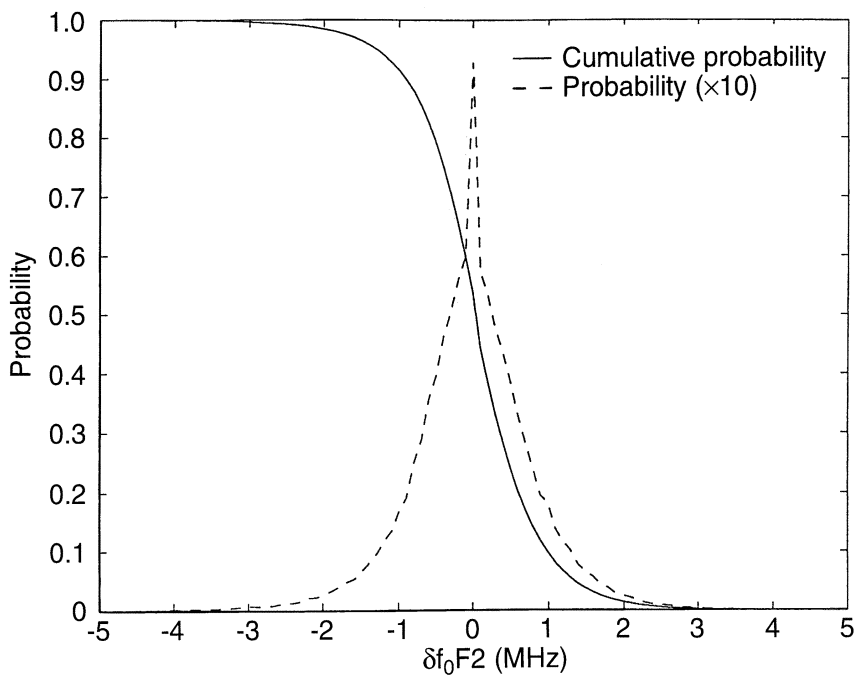

Fig. 2. The distribution of all $\delta f_{\mathrm{o}} F 2$ values observed at Slough for calendar years 1967-1989. The dashed line is the occurrence probability of the $\delta f_{\mathrm{o}} F 2$ value given by the horizontal axis, whereas the solid line is the cummulative probability distribution of $\delta f_{\mathrm{o}} F 2$ exceeding the value on that axis. Note the vertical scale is for the cummulative probability distribution and also applies, but divided by a factor of 10 , for the probability distribution 
advantage of this approach is that $\delta f_{\mathrm{o}} F 2$ is directly proportional to the loss in bandwidth available to the operator of an HF system employing reflections from the F2 layer.

The objective of this study is to look at the effect of the north-south component of the interplanetary magnetic field (IMF) on the critical frequency of the ionospheric $\mathrm{F}$ layer as observed at the mid-latitude station. Because the ionospheric effect is well correlated with geomagnetic disturbance, as seen in a variety of magnetic indices (e.g. Wilkinson, 1995), we also look at the associated geomagnetic response. It is well established that the $B_{z}$ component of the IMF is the most important influence on the magnetosphere and highlatitude ionosphere, as it controls the fraction of the energy in the solar wind flow which is extracted by the magnetosphere. When $B_{z}$ is strongly negative, magnetic reconnection between the IMF and the geomagnetic field produces open field lines which allow mass, energy and momentum to be transferred from the solar wind to the Earth's magnetosphere, as first suggested by Dungey (1961). Many features of the Earth's magnetosphere and high-latitude ionosphere are known to depend on $B_{z}$ in a reference frame which allows for the orientation of the Earth's magnetic axis (such as the GSM frame). These include the cross polar cap potential (the ionospheric signature of the voltage across the magnetosphere) (Reiff et al., 1981; Doyle and Burke, 1983; Wygant et al., 1983; Cowley, 1984; Reiff and Luhmann, 1986); the patterns of the associated high-latitude F-region ionospheric flows (Heelis, 1984; Heppner and Maynard, 1987; Etemadi et al., 1988) and E-region currents (Nishida, 1968; Friis-Christiansen et al., 1985); field aligned currents (Iijima et al., 1978); the average size of the polar cap (Holzworth and Meng, 1984), the occurrence of global geomagnetic activity (e.g. Schatten and Wilcox, 1967; Arnoldy, 1971; Berthelier, 1976; Baker et al., 1981, 1983; Clauer et al., 1981; Bargatze et al., 1985; Scurry and Russell, 1991), including magnetospheric substorms (Rostoker and Falthammer, 1967; Caan et al., 1977; Meloni et al., 1982; Samson and Young, 1986); the occurrence of reconnection signatures such as flux transfer events (Berchem and Russell, 1984) and high speed flow streams at the magnetopause (Scurry et al., 1994); the energy deposition into the high-latitude ionosphere and thermosphere (Akasofu, 1981; Bargatze et al., 1986; Weiss et al., 1992); and the global pattern of winds in the neutral thermosphere (Killeen et al., 1985).

It is the last of these, namely the influence of the IMF on the high-latitude energy deposition and the consequent thermospheric winds, that is of particular significance in the mid-latitude ionosphere. Most of the other phenomena listed are confined to high latitudes. For example, the convective flows and associated currents are confined by the magnetospheric ring current, which shields the mid-latitude ionosphere from the convective electric fields. As a result, the mid-latitude F-region is only weakly affected by these high-latitude electric fields and largely co-rotates with the Earth. The boundary between these two regions of plasma, one convecting and the other co-rotating, is close to the steep magnetospheric plasma density gradient at the plasmapause. The neutral thermosphere however, is not confined by any such a boundary and neutral winds can blow across field lines from high to middle and low latitudes. The high-latitude thermosphere, accelerated by the convecting plasma through ion-neutral momentum transfer and thermal pressure imbalances caused by auroral particle precipitation, generates winds in the mid-latitude thermosphere (Hernandez and Roble, 1978, 1984). Such an affect can clearly be seen in the "storm time circulation" pattern (Duncan, 1969; Mayr and Volland, 1972; Hays et al., 1973). In addition to being accelerated, the high-latitude neutral thermosphere undergoes heating. The latitudinal gradients in the heating result in changes to the global circulation of neutral air and the spatial distribution of molecular-rich air. (Prölss 1980, 1987; Prölss and Römer, 1985). Both the winds and the composition changes (at a fixed pressure level) are known to alter the $\mathrm{F}$ region peak density (Rishbeth, 1975). In the absence of electric fields, the mid-latitude ionospheric plasma is confined to move along the geomagnetic field. A wind blowing meridionally has a component parallel to the magnetic field and this accelerates the plasma by collision. In addition, changes in the neutral composition alter the balance between production and loss in the plasma and this affects the peak density of the ionosphere. An increase in the percentage of molecular neutrals, as would be the case if the thermosphere were heated, would lead to a depletion in the ionospheric density (Seaton, 1956). Such effects have been reproduced by coupled models of the ionosphere - thermosphere system (see reviews by Rees and Fuller-Rowell, 1988; Sojka, 1989) and explain much of the storm-time depletions in the mid-latitude $\mathrm{F}$ layer (e.g. Rishbeth et al., 1987, 1989). It is expected therefore, that since the IMF-controlled flows and precipitation at high latitudes influence the mid-latitude ionosphere (via the neutral thermosphere) that there should exist a relation between the orientation of the IMF and the peak density of the ionospheric $F$ layer at mid latitudes. The proposed mechanism for this process explains the decrease in $f_{\mathrm{o}} F 2$ in terms of composition changes that result as a consequence of the increased energy deposition at high latitudes. Indeed studies of isolated substorms show global changes in ionospheric densities (Park and Meng, 1976). Large ionospheric currents cause joule heating of the atmosphere and if these currents are sufficiently long lived, they can cause an upwelling of the neutral thermosphere, bringing more molecular species such as $\mathrm{N}_{2}$ and $\mathrm{O}_{2}$ to the height of $f_{\mathrm{o}} F 2$. At $\mathrm{F}$ region altitudes, these molecules are converted into molecular ions by charge exchange or ion-atom interchange reactions with oxygen ions and then relatively rapidly undergo dissociative recombination to cause a depletion in the $\mathrm{F}$ region plasma density. If meridional winds move molecular-rich neutral air to lower latitudes, this effect will be seen in ionospheric measurements there. The effects are expected, and indeed observed, to be a function of season (Prölss, 1977, 1980; Wrenn et al., 1987). 
However, there are other mechanisms which can give rise to depletions in the sub-auroral F-region and, in addition, $f_{\mathrm{o}} F 2$ may be increased in positive phases which may have a variety of causes (Prölss et al., 1991; Rishbeth, 1989) and which have a variety of magnitudes and durations. One major mechanism in this respect is the effect of enhanced equatorward thermospheric winds which can lift the plasma to greater altitudes where the recombination chain is slower because fewer neutral molecules are available for the transfer reactions with $\mathrm{O}^{+}$ions.

The possibility that there may be an observable link between the IMF and the behaviour of the mid-latitude ionosphere has led to several investigations (Bremer, 1988; Aravindan and Iver, 1990; Mendillo and Schatten, 1983; Zevakina and Lavrova, 1980; Potapova and Shapiro, 1974; Triskova, 1983). Most of these studies found that changes in the average mid-latitude $f_{\mathrm{o}} F 2$ occurred following a change in the orientation of the IMF. These studies however have mainly been based on the polarity of the sunward component of the IMF, $B_{x}$, i.e. on the toward and away sector boundary crossings. For example, Bremer (1988) employed a superposed epoch study to show that sector boundary crossings were associated with systematic changes in the ionosphere at mid latitudes, similar to the effects in total electron content discovered by Mendillo and Schatten (1983). Sector boundary crossings were determined using high-latitude magnetograms. This inference relies on two facts: that the dawn-dusk IMF component $B_{y}$ is highly anti-correlated with IMF $B_{x}$ (because of the Parker spiral in the IMF) and that the $B_{y}$ component induces east-west Hall currents in the dayside polar cap, because of the tension force of newly-opened field lines (the Svalgaard-Mansurov effect). Bremer (1988) carried out a second study with a small set of IMF data and showed that the sector crossings were, on average, associated with changes in polarity of the northward IMF component, $B_{z}$ as predicted by the work of Russell and McPherron (1973). He ascribed the changes in the mid-latitude ionosphere to these IMF $B_{z}$ changes. We here carry out a similar study, but using direct in-situ measurements of IMF $B_{z}$, rather than sector crossings inferred from ground magnetograms.

We also carry out an initial investigation of the convolution of the effects of IMF orientation with the effects of solar wind dynamic pressure, $P$, on the interaction chain discussed already. This pressure (corresponding to the kinetic energy density of the solar wind flow) has long been understood to be a factor in the development of major geomagnetic storms, as seen in the Dst index (e.g. Burton et al., 1975). Dynamic pressure is also a factor in generalised energy coupling functions used to analyse the dependence of auroral electrojet indices $(A E A L)$ on the interplanetary conditions (Vasyliunas et al., 1982). Increased dynamic pressure has two competing effects: it increases the energy flux of the solar wind incident on the magnetosphere but it also compresses the dayside magnetosphere and the cross sectional area of the magnetosphere presented to the solar wind flow, thereby reducing the total power incident on the magnetosphere. The balance between these two effects is effectively altered by a parameter $\alpha$ introduced by Vasyliunas et al. (1982) which must be determined empirically (Bargatze et al., 1986; Kan and Akasofu, 1982). Kan and Akasofu (1982) found that $\alpha=1$ by assuming that the cross-sectional area of the magnetosphere remains constant. In this case, the generalised coupling function reduces to the often-used epsilon factor (Akasofu, 1981) and the energy coupled into the magnetosphere is predicted to be independent of $P$. However, allowing for the change in the area, Bargatze et al. (1986) found $\alpha=0.5$, for which the input power increases with dynamic pressure as $P^{1 / 6}$. Murayama (1982) found that the $D s t$ index was better predicted by a $P^{1 / 3}$ dependence, which corresponds roughly to $\alpha=0.4$ (for which the power input increases as $P^{4 / 15}$ ). Scurry and Russell (1991) found that efficiency of the magnetic reconnection, responsible for most of the energy extraction, was indeed increased by higher $P$. If the energy extracted from the solar wind (for a given IMF $B_{z}$ and/or clock angle) depends on $P$, we expect the effects of that power extracted on the midlatitude ionosphere to depend on $P$ also.

\section{Method}

For this study, we mainly use hourly ionospheric data from the Slough station (geographic latitude $51 \mathrm{~N}$, longitude $0.2 \mathrm{~W}$ ) because that forms the longest continuous sequence of ionospheric data, reaching back to 1931 . We also make use of 22 years' magnetometer and plasma data from the Interplanetary Monitoring Platform (IMP8) satellite. From hourly averages of the IMF data, all southward turnings of the $B_{z}$ component of the IMF were identified. Note that these events do not include short-period ( $<1 \mathrm{~h}$ ) fluctuations in $B_{z}$. For each event, the change in $B_{z}$ was determined by $\delta B_{z}=B_{z}(t)-B_{z}(t+1 \mathrm{~h})$ where $B_{z}(t)$ is positive and $B_{z}(t+1 \mathrm{~h})$ is negative. The distribution of $\delta B_{z}$ for the events is shown in the cumulative occurrence frequency curve in Fig. 3. From this it can be seen that over 3000 southward turnings with $\delta B_{z} \geq 2 \mathrm{nT}$ were identified in the period November 1963 to December 1987. This falls to about 1000 events for $\delta B_{z} \geq 6 \mathrm{nT}$ and under 100 for $\delta B_{z} \geq 14 \mathrm{nT}$. In order to define the ionospheric response to these IMF changes as clearly as possible, the largest of these events were selected. We chose a threshold of $\delta B_{z} \geq 11.5 \mathrm{nT}$, this being a compromise between studying the largest, most clear-cut events, and maintaining a large enough sample of the data to be statistically useful. This threshold gave a set of 150 events. The effect of varying this threshold was also investigated.

The north-south component of the IMF $B_{z}$ controls the coupling of the solar wind to the magnetosphere, but also of relevance to the high-latitude energy deposition is the energy density of the solar wind flow. Because this is dominated by the bulk flow of the solar wind plasma this is roughly equal to $m n v^{2} / 2=P / 2$, where $n$ is the solar wind density, $m$ the mean mass, $v$ the velocity and 


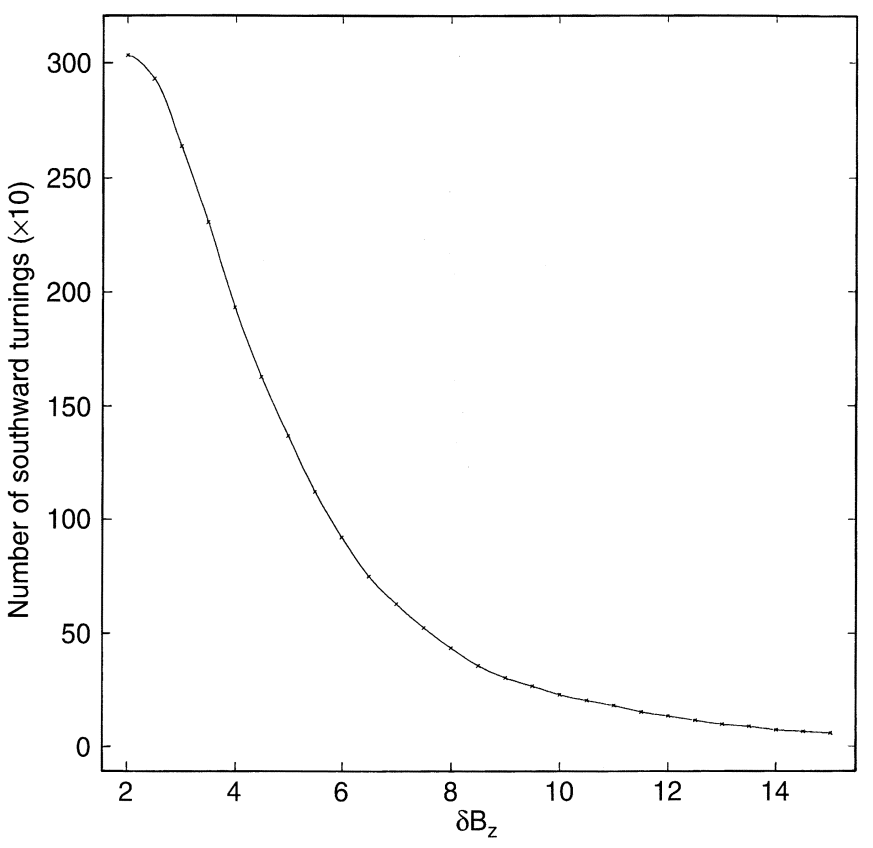

Fig. 3. The number of southward turnings with the change in the hourly $B_{z}$ values, $\delta B_{z}$, exceeding a given value for the years 1967-1989

$P$ the dynamic pressure. The largest $\delta B_{z}$ events are when both $B_{z}(t)$ and $B_{z}(t+1 \mathrm{~h})$ are large in magnitude. Bowe et al. (1990) showed that large $\left|B_{z}\right|$ was highly correlated with large solar wind dynamic pressure, $P$. This means the southward turning events will tend to be accompanied by large $P$. A threshold for the peak $P$ (usually seen at or near the time of the southward turning) of $5 \mathrm{nPa}$ was set as it divided the set for $\delta B_{z} \geq 11.5 \mathrm{nT}$ into two approximately equal size subsets. Superposed epoch studies were then carried out for those southward turnings with $\delta B_{z} \geq 11.5 \mathrm{nT}$ which were accompanied by a solar wind pressure of $P>5 \mathrm{nPa}$ and those where the concomitant pressure was $\leq 5 \mathrm{nPa}$. A more detailed study of the effects of solar wind dynamic pressure will be presented at a later date: the above division of the dataset is, however, sufficient to reveal that $P$ plays a key role in determining the geomagnetic and ionospheric response to southward turnings of the IMF. Inspection of parts (a) of Fig. 4 and 5 shows the mean $B_{z}$ variation for these two subsets is very similar for the times within the three hours of the southward turning but there are slight differences, with a gradual build up and decay occurring before and after this time for the high $P$ subset.

Taking the southward turning to be time $t=0$, the average behaviour of $B_{z}, P, K_{p}$, Dst and $A E$, and the change in ionospheric $\mathrm{F}$ region critical frequency at Slough, $\delta \mathrm{f}_{\mathrm{o}} F 2$, were studied for four days either side of the event. This was achieved by averaging each quantity in 1-hour bins of $t$. The results are shown in Figs. 4 and 5 where each panel shows the variation of the mean for that parameter, over $-96<\mathrm{t}<+96 \mathrm{~h}$. Each mean is plotted as a point, with a bar which is plus and minus the standard deviation in the mean. Figure 4 is for all cases for which peak $P$ exceeded $5 \mathrm{nPa}$, Fig. 5 for those cases where $P \leq 5 \mathrm{nPa}$. The top left panel shows the mean variation of IMF $B_{z}$. This shows a bipolar signature, with $\left\langle\delta B_{\mathrm{z}}\right\rangle$ of about $15 \mathrm{nT}$ in both cases. Note that $B_{z}$ tends to be strongly positive prior to these large $\delta B_{z}$ cases and that mean $P$ increases with mean $\left|B_{z}\right|$. In Fig. $4,<P>$ peaks at over $8 \mathrm{nPa}$ at $t=0$, whereas in Fig. 5 there is a much weaker peak of 3.5 $\mathrm{nPa}$. In both cases the rise in $\langle P>$ starts about 1 day before the southward turn and last until one day after. For the high pressure cases, $\left\langle B_{z}\right\rangle$ is positive for about 1 day prior to the southward turning, and negative for about 1 day after it, although the largest mean values around the time of the turning last for only $1-2 \mathrm{~h}$. Only this second, bipolar spike-like feature is seen for the low pressure cases.

\section{The geomagnetic indices}

In order to understand the response of the geomagnetic indices to the southward turning of IMF $B_{z}$, it is necessary to make a few points about how they are compiled and what conditions would induce them to change. The three indices used in this study are based on measurements made by ground-based magnetometers. Each of the indexes is compiled from instruments which lie in a restricted range of geomagnetic latitudes.

The planetary $K$ index, $K_{p}$, is the mean of twelve midlatitude (between 48 and $62^{\circ}$ geomagnetic latitude) observing stations. The $K$ index for each station is the range of field values in each 3-h period. In this way, the background diurnal variations are separated from times of magnetic activity. The $K$ index is approximately logarithmic, with a maximum value of 9. Each level of $K_{p}$ is further divided into a plus, zero and minus subsection, e.g. 5+, 5o and 5- which we here quantify as 53,50 and 47 . As a result, the $K_{p}$ index, as represented in this work, extends from 0 to 90 . The combination of high conductivity and high electric field in the auroral oval causes the auroral electrojets which are sensed by magnetometer stations at high latitudes (60 to 71 geomagnetic latitude), largely from the effect of the Hall currents. The difference of peak positive and negative disturbances seen by a ring of 12 selected stations is called auroral electrojet $(A E)$ index. The $A E$ index is, to some extent, enhanced by increased electric fields, ie by the high-latitude convection, but the major features are large increases caused by strong precipitation (giving high conductivities) in the presence of electric fields during substorm expansion phases. A ring of stations near the equator remotely sense the ring current around the Earth in the inner magnetosphere, and are used to generate the $D s t$ index.

To give some idea of the typical variability of $B_{z}$ and the geomagnetic indices, in Fig. 6 we plot the cumulative probability distributions for each. These are shown in the same format as Fig. 2. These will be used later in the study to put a given size disturbance into context by its overall occurrence frequency. 

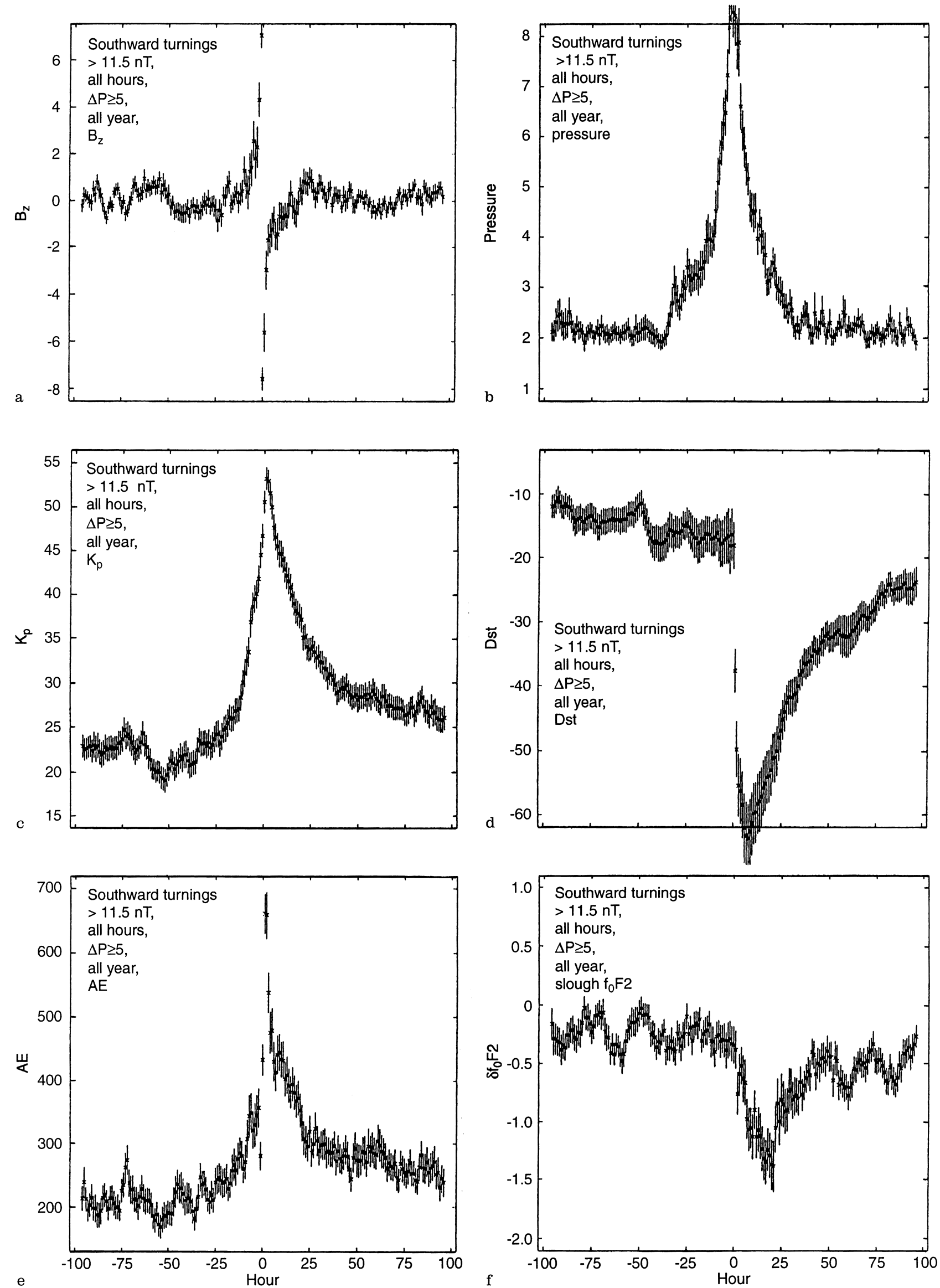


\section{Results}

The most striking feature of the behaviour of $B_{z}$ in Fig. $4 \mathrm{a}$ and $5 \mathrm{a}$ is that in order to achieve a large southward turning, the IMF must first increase northward by the order of $8 \mathrm{nT}$ before reversing to a southward field of $-8 \mathrm{nT}$. The persistence of $B_{z}$ is such that an increase in average values above zero starts around $24 \mathrm{~h}$ before reversal and the decline in negative $B_{z}$ continues up to $24 \mathrm{~h}$ afterwards. If we compare with the probability distribution shown in Fig. 6a, we find that such a large magnitude of $B_{z}$ is rare, with $B_{z}>+8$ $\mathrm{nT}$ and $<-8 \mathrm{nT}$ for only $2.5 \%$ of the time in each case.

\subsection{The effect on $K_{p}$}

It can be seen in both Figs. $4 \mathrm{c}$ and $5 \mathrm{c}$ that $K_{p}$ rises before the southward turning of the IMF, roughly with the rise in the solar wind dynamic pressure, $P$. It decays more slowly than it rises, after the southward turning and remains elevated even after $96 \mathrm{~h}$. To some extent, this reflects the fact that $K_{p}$ is correlated with both southward IMF and $P$. The mean $K_{p}$ peaks in the same hour as the southward turning at values near $53(5+)$ and $43(4+)$ for $P>5 \mathrm{nPa}$ and $P \leq 5 \mathrm{nPa}$, respectively. From Fig. $6 \mathrm{~b}$ we see that $K_{p}$ exceeds these values for $13 \%$ and $30 \%$ of the time.

\subsection{The effect on Dst}

In both Fig. $4 \mathrm{~d}$ and $5 \mathrm{~d}$, Dst averages about $-15 \mathrm{nT}$ prior to the southward turning. Unlike $K_{p}$, however, this mean $D s t$ is almost completely unaffected until the time of the southward turning, at which point it decreases rapidly to values below $-60 \mathrm{nT}$ and $-35 \mathrm{nT}$ for $P>5$ $\mathrm{nPa}$ and $P \leq 5 \mathrm{nPa}$, respectively. This represents a significant enhancement of the ring current. Figure $6 \mathrm{c}$ shows that such enhancements occur for only about 5\% and $30 \%$ of the time. The decay of the ring current is a complex combination of several ion loss processes, some of which have long time constants. By $t=96 \mathrm{~h}, D s t$ has still not recovered to the initial value and remains at about $-25 \mathrm{nT}$. The average $D s t$ values show the classic form of a negative or main phase of a magnetic storm. Individual magnetic storms often start with a short-lived positive phase as the field is compressed. No clear positive phase can be seen in either Figs. $4 \mathrm{~d}$ or $5 \mathrm{~d}$. This implies that the factors generating the positive phase do not bear a fixed relation to the southward turning of the IMF (Burton et al., 1975). The sudden decrease of Dst

Fig. 4a-f. Superposed epoch study for southward turnings with $\delta B_{z}>11.5 \mathrm{nT}$ and peak solar wind dynamic pressure $P>5 \mathrm{nPa}$ for 1967-1989. Plots are for a $B_{z}, \mathbf{b} P$, c $K_{p}$, d $D s t$, e $A E \mathbf{f} \delta \mathrm{f}_{\mathrm{o}} F 2$. Time zero is the time of the southward turning; points are the mean value for each time bin and error bars are plus and minus one standard deviation in the mean starts at $t=0.5 \mathrm{~h}$ and $D s t$ reaches minimum values at about $t=8 \mathrm{~h}$.

\subsection{The effect on $A E$}

The studies discussed in the introduction, and many others, provide clear evidence that $A E$ is enhanced by a prior period of southward $B_{z}$, in the form of isolated substorms (with $A E$ enhancements in the expansion and recovery phases lasting about one hour) or sequences of multiple substorms if the IMF remains southward. There is a delay of about $0.5-1 \mathrm{~h}$ prior to the onset of the expansion phase, i.e. the growth phase. This can indeed be recognised in Fig. 4e and 5e, in which a pulse of enhanced $A E$ is seen for $1-2 \mathrm{~h}$ after the southward turning, with peak values of $650 \mathrm{nT}$ and $560 \mathrm{nT}$ for $P>5 \mathrm{nPa}$ and $P \leq 5 \mathrm{nPa}$, respectively. From Fig. 6d, hourly $A E$ exceeding these values occurs only $7 \%$ and $12 \%$ of the time.

The behaviour of $A E$ is more complex than $K_{p}$ or $D s t$ however, since there is an initial rise in $A E$ which starts about $24 \mathrm{~h}$ before the southward turning. There is a short-lived minimum immediately before the pulse discussed in both cases, and after the pulse, $A E$ decays slowly from an elevated value, rather like $K_{p}$. Also as with $K_{p}$, values are still elevated at $t=96 \mathrm{~h}$. This latter effect is probably due to the ring current having an effect on the high-latitude stations. The high values immediately after the pulse probably result from the average southward IMF remaining negative for several hours and the fact that the energy stored in the magnetotail during a period of southward IMF may not all be lost in a single period of substorm activity.

\subsection{The effect on $\delta f_{\mathrm{o}} F 2$}

Prior to the southward turning, $\delta f_{\mathrm{o}} F 2$ shows slightly negative mean values. The reasons for this are not yet clear, but it may be a result of large $\delta B_{z}$ southward turnings tending to occur during periods of generally enhanced solar wind dynamic pressure, $P$. The average of $\delta f_{\mathrm{o}} F 2$ prior to the southward turning is about $-0.25 \mathrm{MHz}$ which is a depletion which Fig. 2 shows to be exceeded roughly $35 \%$ of the time. This enhanced pressure may have other effects, for example the decay in Dst may be initially opposed by the compressive effect of enhanced $P$.

In Fig. $4 \mathrm{f}$ there is a clear decay in $\delta f_{\mathrm{o}} F 2$ following the southward turning and the enhanced energy input to high latitudes, as indicated by the $A E$ index. The largest amplitude of the effect is about $1.4 \mathrm{MHz}$, and from Fig. 2, larger depletions (lower $\delta f_{\mathrm{o}} F 2$ values) are seen for only $3 \%$ of the time. The minimum densities are seen roughly $20 \mathrm{~h}$ after the southward turning, by when Dst is recovering and $A E$ has dropped to the weak enhanced values that appear to be due to the ring current and not substorm activity. The recovery takes place gradually over the next 3 days, over which the mean $\delta f_{\mathrm{o}} F 2$ shows a marked diurnal cycle which will be discussed in the next section. 

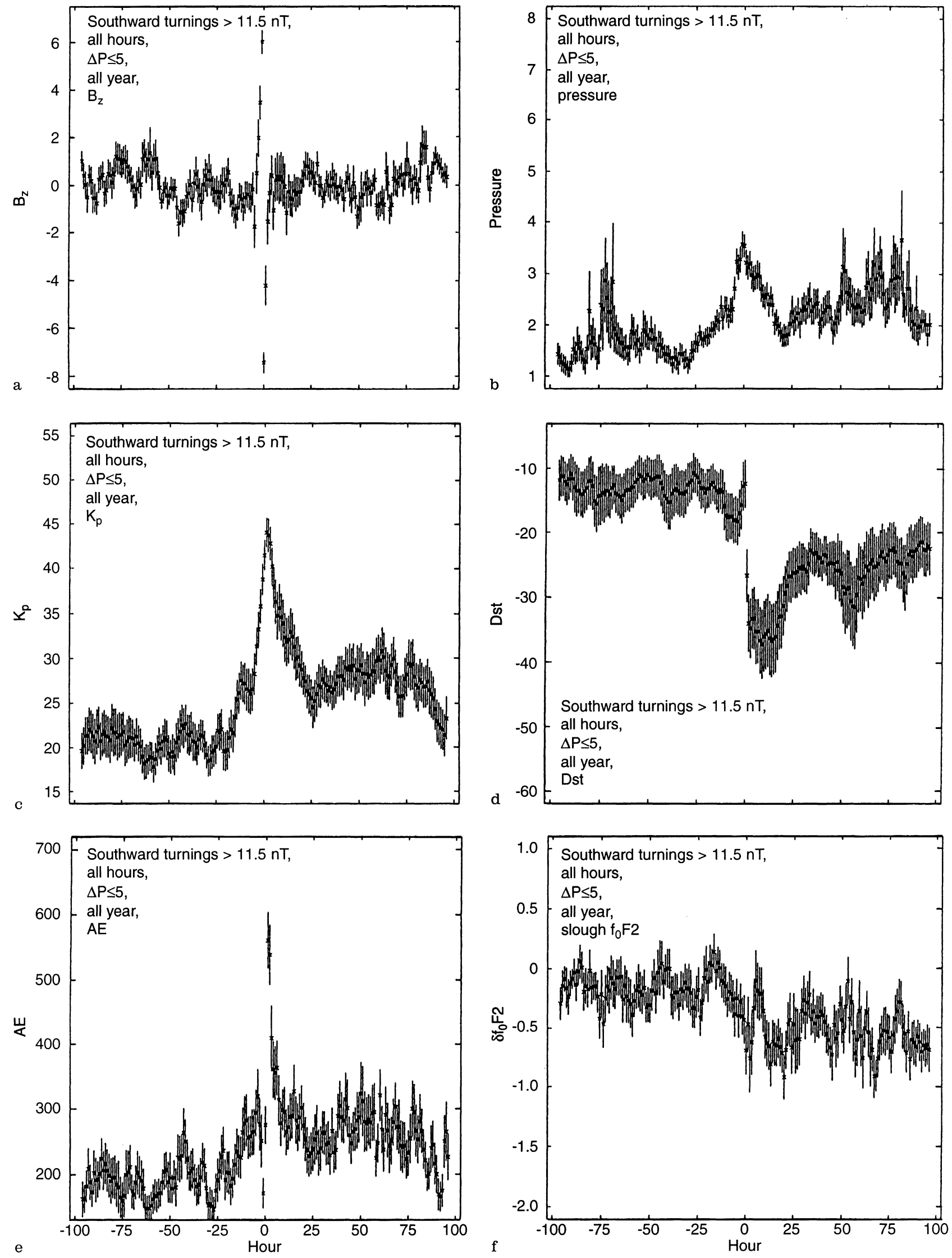

Fig. 5a-f. Same as Fig. 4, for $\delta B_{z}>11.5 \mathrm{nT}$ and $P \leq 5 \mathrm{nPa}$ 
The same study, carried out for $P \leq 5 \mathrm{nPa}$ is shown in Fig. 5f. The results show a slight depression of $f_{\mathrm{o}} F 2$ values after the southward turning, but without the clear negative storm-type effects seen in Fig. 4f. It is thus immediately clear that although negative IMF $B_{z}$ is important in enabling the extraction of solar wind energy and thus driving global ionosphere/thermosphere disturbances, the solar wind energy density (proportional to $P$ ) must be high for coherent changes to be seen at mid latitudes. The full dependence of $\delta f_{\mathrm{o}} F 2$ prior to the southward turning appears to be largely a summer phenomenon. The summer data show a minimum of $\delta f_{\mathrm{o}} F 2$ at $-1.7 \mathrm{MHz}$ and at time $t=13 \mathrm{~h}$, i.e. deeper and earlier than for the averages for all times of year. The winter cases produce a shorter-lived depression of $f_{\mathrm{o}} F 2$, with minimum $\delta f_{\mathrm{o}} F 2$ at $-1.2 \mathrm{MHz}$ and at time $t=23 \mathrm{~h}$, i.e. less deep and later than for both the summer and allyear plots.

In order to confirm these findings a similar study was carried out using Argentine Island, a Southern Hemisphere station at geographic latitude -65.3 and longitude 295.8. The results are shown in Fig. 7c, d. In this case, the summer depletion was again much clearer, with a minimum $\delta f_{\mathrm{o}} F 2$ of $-1.8 \mathrm{MHz}$ at $t=15 \mathrm{~h}$. The winter effect is weaker, indeed it is very weak with $\delta f_{\mathrm{o}} F 2$ falling to only $-0.6 \mathrm{MHz}$. Thus comparison with Argentine Island confirms some of the effects reported for Slough are common to other stations, but the behaviour appears to vary with location. A study is now underway to analyse further stations in the way presented here.

One possible factor in $\delta f_{\mathrm{o}} F 2$ values, in addition to the changes produced by thermospheric composition variations, is the latitude of the mid-latitude trough (in ionospheric density), with respect to the station. This trough lies equatorward of the auroral oval and poleward of the co-rotating mid-latitude ionosphere (e.g. Spiro et al., 1978). Following southward turning of the IMF, the expansion of the convection pattern causes the trough to move to lower latitudes and this may sometimes contribute to the drop in $\delta f_{\mathrm{o}} F 2$ values seen at Slough. However, the trough shows a strong seasonal variation being weak or absent in summer. This is not consistent with the seasonal variations shown in Fig. 7.
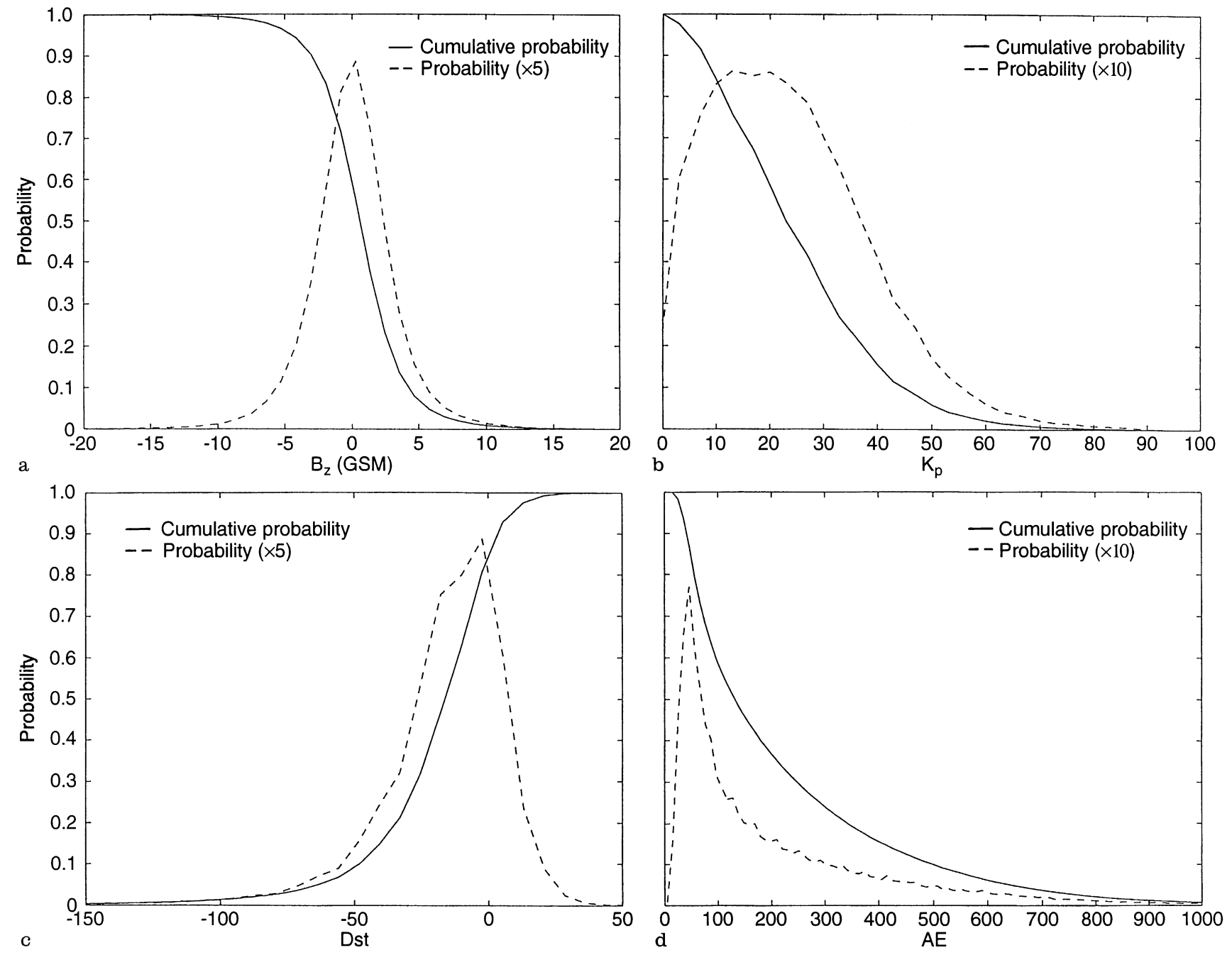

Fig. 6a-d. As for Fig. 2 for a $B_{z}$, b $K_{p}$, c $D s t$ and $\mathbf{d} A E$ 
In addition, the trough is predominantly a nightside phenomenon, whereas the $\delta f_{\mathrm{o}} F 2$ variations shown tend to peak when Slough is near noon.

\subsection{The effect of the timing of the southward turning}

Park and Meng (1976) report depressions in $f_{\mathrm{o}} F 2$ caused by isolated substorms which form in the noon local time sector and then co-rotate with the Earth. From a statistical survey, Hargreaves and Bagenal (1977) found co-rotating and evolving regions of positive and negative storm phases. Such results mean that there should be, for any one station, a variation in the size of the depletion with the UT of the southward turning.
Generally there is an expectation that substorms taking place when the station is on the nightside will have greatest effect, but that effect only becomes apparent when the station rotates through sunrise onto the dayside. Figure 8 shows the effect of grouping the data according to the UT of the southward turning, again for the case of $\delta B_{z}>11.5 \mathrm{nT}, P>5 \mathrm{nPa}$ (Fig. 4f). The four cases Fig. $8 \mathrm{a}-8 \mathrm{~d}$ are for southward turnings in the UT ranges $03-09,09-15,15-21$ and $21-03 \mathrm{~h}$.

The depression of $f_{\mathrm{o}} F 2$ is seen in all cases but the behaviour is very different in each case. The deepest depression is seen in Fig. 8c, for which the Slough station will be in the dusk/pre-midnight sector at the time of the southward turning (15-21 h. UT) and the pulse of enhanced $A E$ commencing roughly one hour

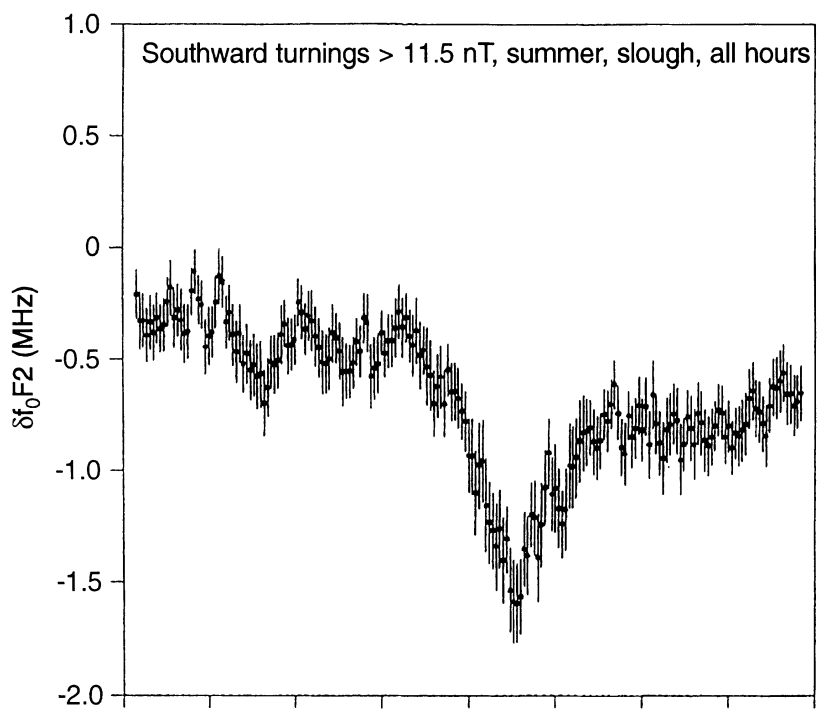

a
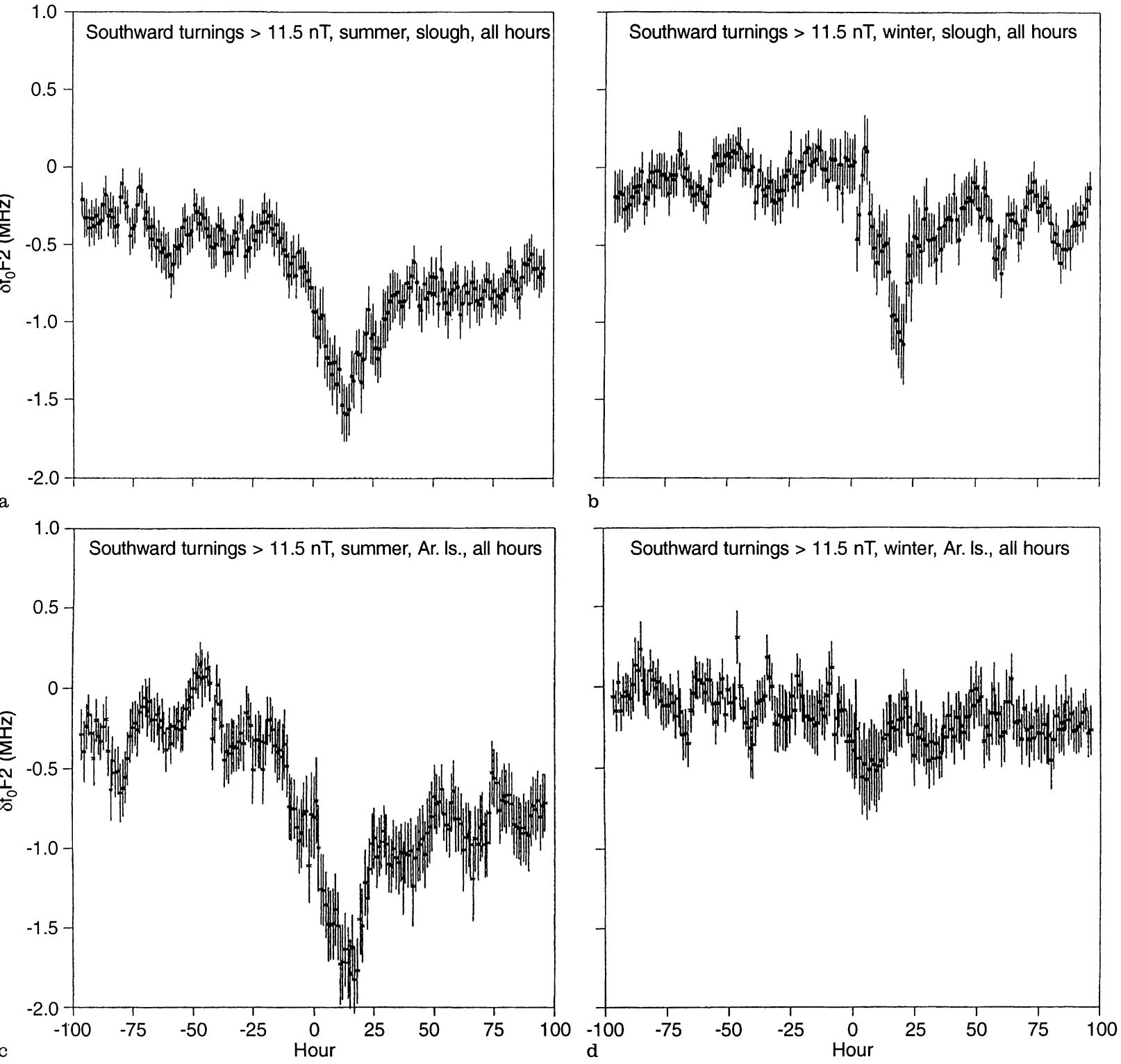

Fig. 7a-d. Same as Fig. 4(f) for 30 day periods around summer solstice (a and c) and winter solstice (b and $\mathbf{d})$. $\mathbf{a}$ and $\mathbf{b}$ are for Slough and $\mathbf{c}$ and $\mathbf{d}$ are for Argentine Island 
later. A small ionospheric depletion is seen at the time of the $A E$ pulse ( $t$ equal to $1-2 \mathrm{~h}$ ), when the station is in the pre-midnight sector. In this case, the peak depletion is $2 \mathrm{MHz}$ at time $t=18 \mathrm{~h}$. By this time, Slough will have rotated into the noon sector. Minima in $\delta f_{\mathrm{o}} F 2$ are seen on the next three days when Slough returns to the noon sector, while nighttime $\delta f_{\mathrm{o}} F 2$ returns to near the same values seen prior to the southward turn $\left(\delta f_{\mathrm{o}} F 2 \approx-0.2 \mathrm{MHz}\right)$. Figure $8 \mathrm{~d}$ is for southward turnings at 21-03UT, when Slough is in the midnight sector. In this case the deepest depletion is $-1.6 \mathrm{MHz}$ at $t=13$ $\mathrm{h}$, when, as for the case in Fig. 8c, Slough has rotated into the noon sector. Although a depletion is seen 48 and $72 \mathrm{~h}$ later, when Slough again returns to the noon sector, only a very weak minimum is seen on the first day at this UT. This effect appears to be real as it is found in the data for each of the 2 sunspot cycles when analysed separately: however the reasons for this are not known. Figure 8a is for turnings at 03-09 UT, when Slough is in the dawn sector. In this case, the depletion appears to start even before the southward turning, but this is probably because the depletion in this case is small $(-0.8 \mathrm{MHz})$ and comparable in magnitude to the other fluctuations seen during the 96 hours, prior to the turning. The depletion lasts throughout the next 24 hours maintaining large $(\approx 0.8 \mathrm{MHz})$ values even through the night, and the largest depletion $(-1.2 \mathrm{~h})$ is seen when Slough returns to the noon sector at $t=28 \mathrm{~h}$. Weak minima are then seen each time the station subsequently returns to the dayside sector. Figure $8 \mathrm{~b}$ is for turnings at $09-15$ UT when Slough is in the noon sector. This is the one time in all the superposed epoch studies presented here that a positive phase is seen, with enhanced values (positive $\delta f_{\mathrm{o}} F 2$ ) peaking at $t=6 \mathrm{~h}$,

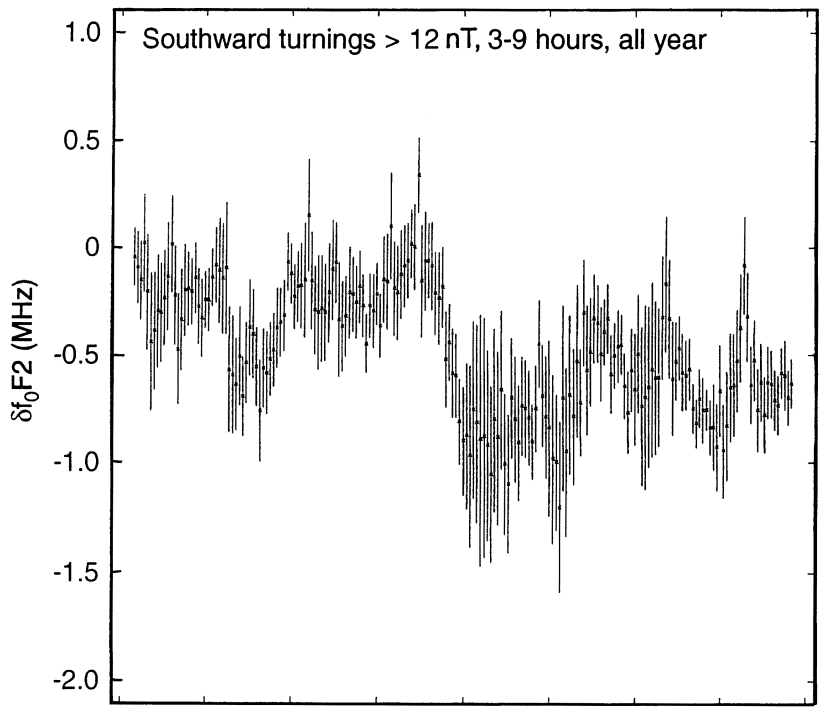

a

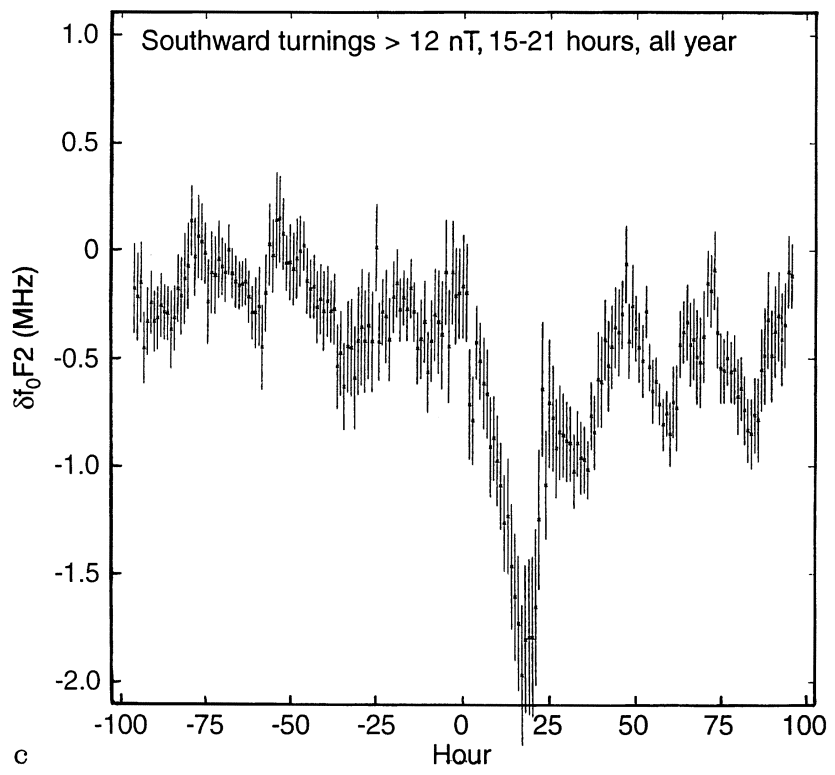

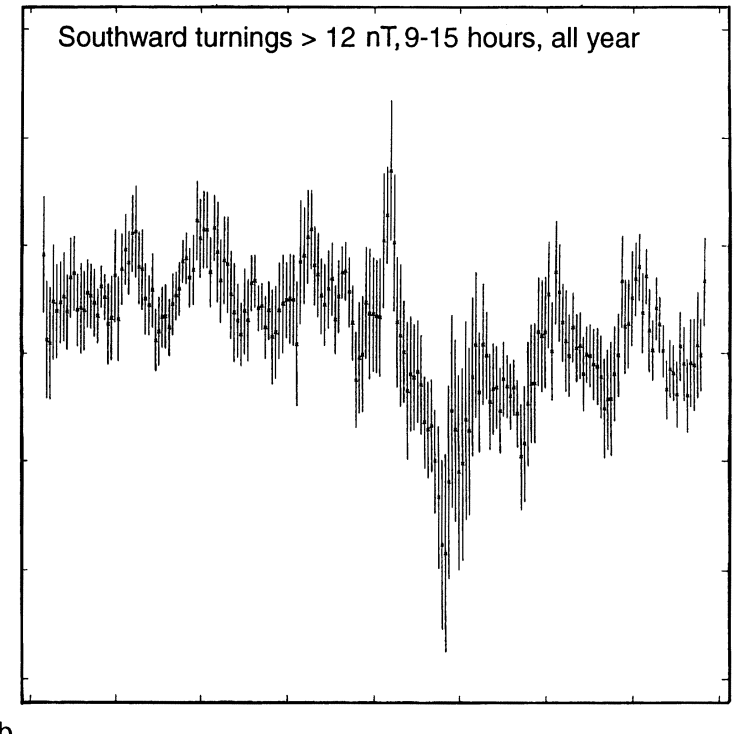

b

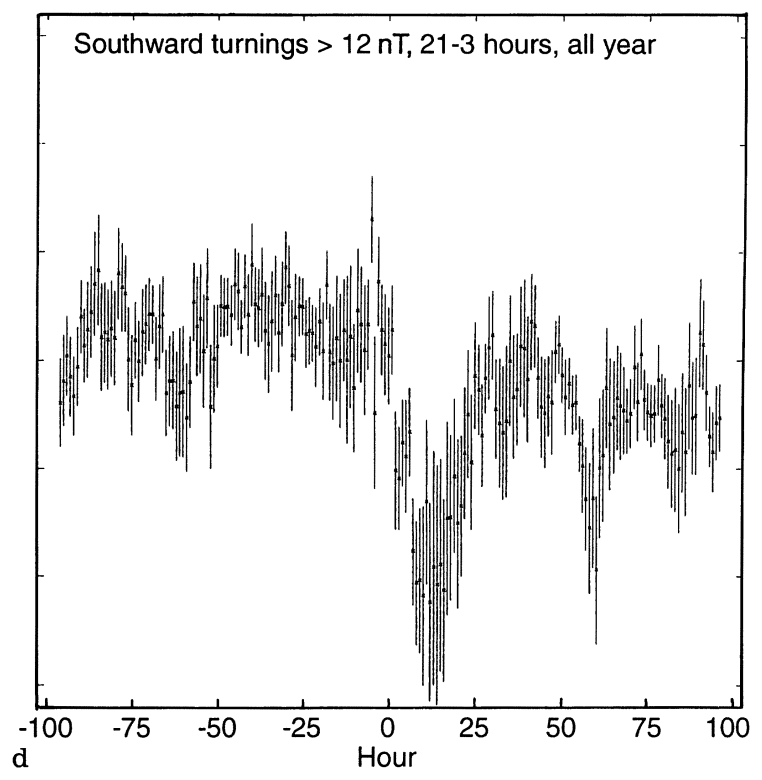

Fig. 8a-d. Same as Fig. 4(f) for southward turnings in the intervals a 03-09 UT, b 09-15 UT, c 15-21 UT and d 21-03 UT 
when Slough is near dusk (Hargreaves and Bagenal, 1977). A clear minimum is seen at $t=23 \mathrm{~h}$, and each subsequent time that the station returns to the noon sector, each minimum being weaker than the previous one as the ionosphere recovers.

\subsection{Response magnitudes as a function of the change in $B_{z}$}

These studies were carried out using the arbitrarilychosen threshold for $\delta B_{z}$ of $11.5 \mathrm{nT}$. Figure 9 investigates the effect of this choice of threshold. Parts $\mathrm{a}, \mathrm{b}$ and c show, respectively, the minimum value of $D s t$ in the storm depletion following the southward turn, the maximum of $A E$ in the burst immediately after the southward turn and the subsequent minimum $\delta f_{\mathrm{o}} F 2$. The number of cases as a function of the $\delta B_{z}$ threshold is shown in Fig. 3. It can be seen that the effect on Dst, $A E$ and $\delta f_{\mathrm{o}} F 2$ all increase systematically with increasing $\delta B_{z}$. Note that the plot is as a function of $\delta B_{z}$ threshold: large $\delta B_{z}$ events will be included along with lower $\delta B_{z}$ events as the threshold is lowered. This means that the dependence on $\delta B_{z}$ value (rather than threshold) will be steeper than shown in Fig. 9.

\section{Conclusions}

We have studied the ionospheric and geomagnetic response of large southward turnings of the IMF, selected by the magnitude of the turning in hourly data. This set was then subdivided into two sets relating to large and small associated changes of the solar wind dynamic pressure. It was found that the response of the three magnetic activity indices followed similar trends in the two sets, but that for those events accompanied by small changes in the solar wind dynamic pressure, the magnitude of the effects was much reduced. The response of $f_{\mathrm{o}} F 2$ was especially strongly dependent on the solar wind dynamic pressure, with little effect being seen when the pressure change was small. The results are consistent with the mechanism for the depletion of $\mathrm{F}$ region plasma density caused by enhanced solar wind magnetosphere coupling: this causes enhanced energy deposition in the high-latitude thermosphere, upwelling in response to the heating and transport of molecularrich air from the auroral zone to mid latitudes, where it alters the ion chemistry and leads to dissociative recombination of molecular ions. The depletion is greater in summer than in winter and is also seen when the station rotates around into the noon sector. For Slough, southward turnings taking place in the 15-21 UT range have the most effect, for which the station is in

Fig. 9a-c. The geomagnetic and ionospheric responses as a function of the threshold size of the $B_{z}$ change in the southward turning $\delta B_{z}$ : a the minimum in Dst; $\mathbf{b}$ the maximum in $A E$ and $\mathbf{c}$ the minimum in $\delta f_{\mathrm{o}} F 2$

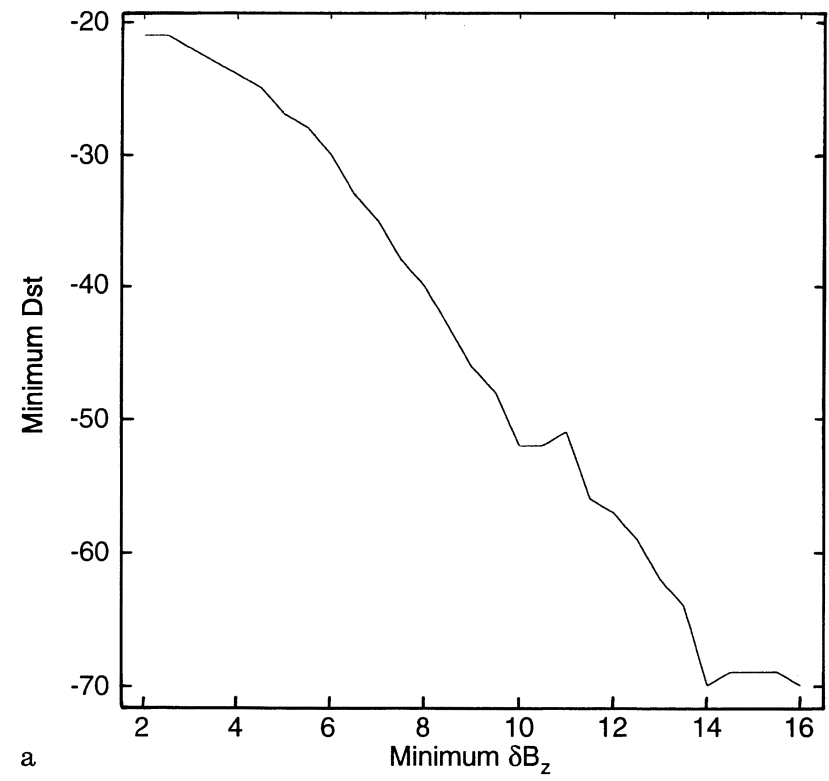

a
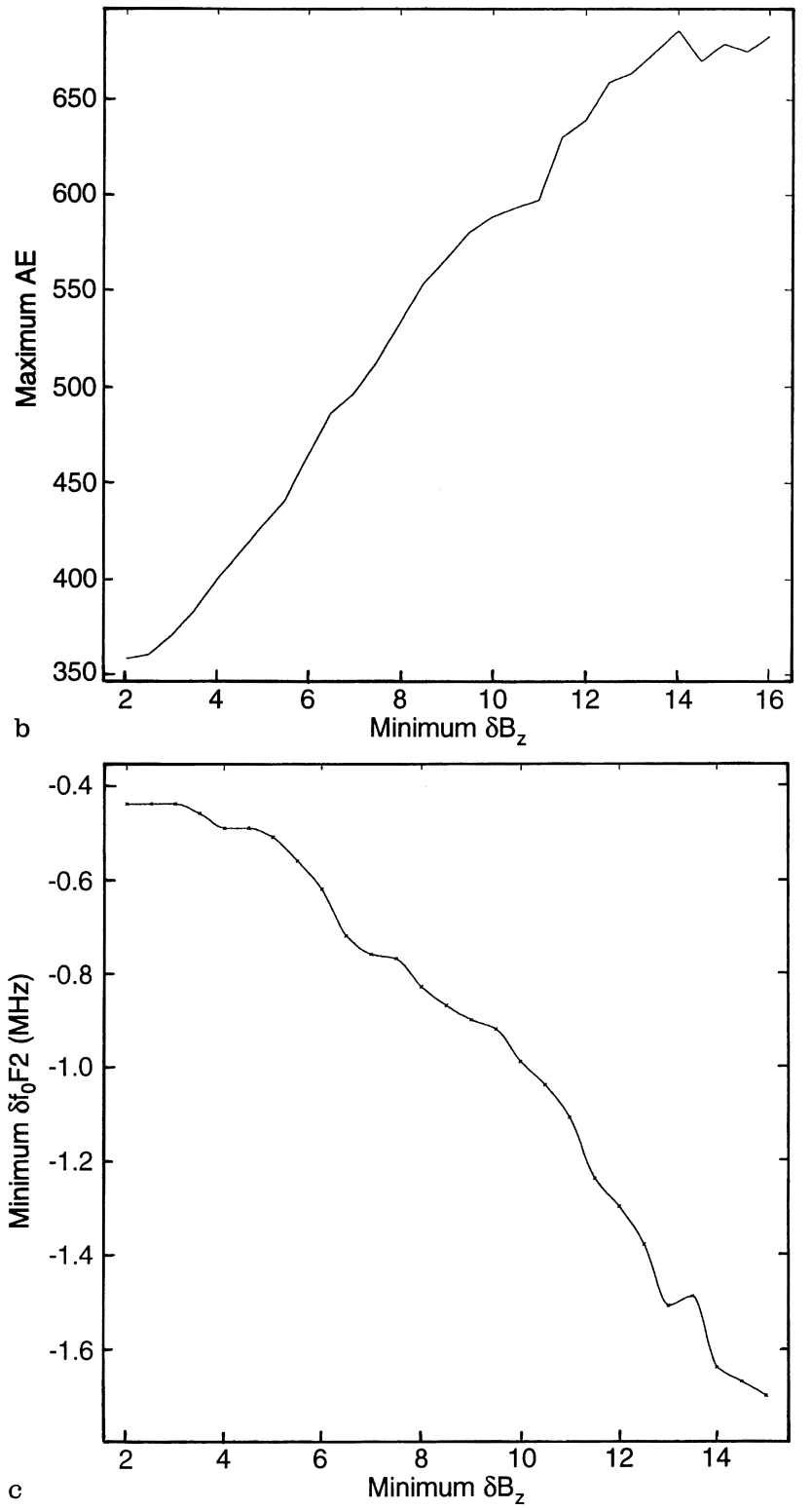
the dusk/pre-midnight sector at the time of the substorms which result from the southward turning.

Comparison with the occurrence distributions of the various parameters shows that the events studied are large and quite rare, for most parameters the effects are only exceeded less than $10 \%$ of time. However, analysis for smaller thresholds of the change in the IMF $B_{z}$ shows the same effects but with reduced magnitude. This implies that the storm time changes and much of the day-to-day variability of the ionosphere have similar, if not the same, causes and the difference would then be largely one of degree.

Acknowledgement The authors thank NSSDC at Goddard Space Flight Centre for compiling the Omnitape data on the interplanetary medium. This study has used the IMP-8 IMF data supplied by R. P. Lepping of GSFC and the plasma data supplied by A. Lazarus of M.I.T. We thank WDC-C2, Kyoto for the $A E$ data and for the Dst data which were supplied, along with other geophysical parameters by the World Data Centre C1 for Solar Terrestrial Physics at RAL. This study also employs the long data sequence from the Slough ionosonde and our thanks go to J. A. Smith at RAL for maintaining that data sequence over the last sunspot cycle. This work was supported by the UK Particle Physics and Astronomy Research Council.

Topical Editor D. Alcaydé thanks J. Kelly and another referee for their help in evaluating this paper.

\section{References}

Akasofu, S. I., Energy coupling between the solar wind and the magnetosphere, Space Sci. Rev., 28, 121-190, 1981.

Aravindan, P., and K. N. Iyer, Day-to-day variability in ionospheric electron content at low latitudes, Planet. Space. Sci., 38, 743$750,1990$.

Arnoldy, R. L., Signature in the interplanetary medium for substorms, J. Geophys. Res., 76, 5189-5201, 1971.

Baker, D. N., E. W. Hones, Jr., J. B. Payne, and W. C. Feldman, A high time resolution study of interplanetary parameter correlations with AE, Geophys. Res. Lett., 8, 179-182, 1981.

Baker, D. N., R. D. Zwickl, S. J. Bame, E. W. Hones, Jr., B. T. Tsurutani, E. J. Smith, and S. -I. Akasofu, An ISEE-3 high time resolution study of the interplanetary parameter correlations with magnetospheric activity, J. Geophys. Res., 88, 6230-6242, 1983.

Bargatze, L. F., D. N. Baker, R. L. McPherron, and E. W. Hones, Jr., Magnetospheric impulse response for many levels of geomagnetic activity, J. Geophys. Res., 90, 6387-6394, 1985.

Bargatze, L. F., R. L. McPherron, and D. N. Baker, Solar wind magnetosphere energy input functions, in Solar wind magnetosphere coupling eds. Y. Kamide and J. Slavin, pp 101-109, Terra Scientific, Tokyo, 1986.

Berchem, J., and C.T. Russell, Flux transfer events on the magnetopause: spatial distribution and controlling factors, J. Geophys. Res., 89, 6689-6703, 1984.

Berthelier, A., Influence of the polarity of the interplanetary magnetic field on the annual and the diurnal variations of magnetic activity, J. Geophys. Res. 81, 4546-4552, 1976.

Bowe, G. A., M. A. Hapgood, M. Lockwood, and D. M. Willis, Short-term variability of solar wind number density, speed and dynamic pressure as a function of the interplanetary magnetic field components: a survey over two solar cycles, Geophys. Res. Lett., 17, 1825-1828, 1990.

Bradley, P. A., Improvements in the propagation prediction method to be used for HF broadcasting, ITU Telecommun. J., 58, (9), 558, 1991.

Bremer, J., The influence of the IMF structure on the ionospheric F-region, J. Atmos. Terr Phys. 50, (9), 831-838, 1988.
Burton, R. K., R. L McPherron, and C. T. Russell, An empirical relationship between interplanetary conditions and Dst, J. Geophys. Res., 80, 4204-4214, 1975.

Caan, M. N., R. L. McPherron, and C. T. Russell, Characteristics of the association between the interplanetary magnetic field and substorms, J. Geophys. Res., 82, 4837-4842, 1977.

Clauer, C. R., R. L. McPherron, C. Searles, and M. G. Kivelson, Solar wind control of auroral zone magnetic activity, Geophys. Res. Lett., 8, 915-918, 1981.

Cowley, S. W. H., Solar wind control of magnetospheric convection, in Achievements of the international magnetospheric study, IMS, pp 483-494, ESA SP-217, ESTEC, Noordwijk, The Netherlands, 1984.

Doyle M. A., and W. J. Burke, S3-2 measurements of polar cap potential, J. Geophys. Res., 88, 9125-9133, 1983.

Duncan, R. A., F-region seasonal and magnetic-storm behaviour, J. Atmos. Terr. Phys. 31, 59-70, 1969.

Dungey, J. W., Interplanetary magnetic field and the auroral zones, Phys. Rev. Lett., 6, 47-48, 1961.

Etemadi, A. S., W. H. Cowley, M. Lockwood, B. J. I. Bromage, D. M. Willis, and H. Luehr, The dependence of high-latitude dayside ionospheric flows on the north-south component of the IMF, a high time resolution correlation analysis using EISCAT "POLAR" and AMPTE UKS and IRM data, Planet. Space Sci., 36, 471-498, 1988 .

Friis-Christensen, E., Y. Kamide, A. D. Richmond, and S. Matsushita, Interplanetary magnetic field control of highlatitude electric fields and currents determined from Greenland magnetometer data, J. Geophys. Res.,90, 1325-1338, 1985.

Hargreaves, J. K. and F. Bagenal, The behaviour of the electron content during ionospheric storms: a new method of presentation and comments on the positive phase, J. Geophys. Res., 82, 731-734, 1977.

Hays, P. B., et al. Auroral heating and the composition of the neutral atmosphere, Planet. Space. Sci., 21, 559-573, 1973.

Heelis, R. A., The effects of interplanetary magnetic field orientation on dayside high-latitude convection, J. Geophys. Res., 89, 2873-2880, 1984.

Heppner, J. P. and N. C. Maynard, Empirical high-latitude electric field models, J. Geophys. Res., 92, 4467-4489, 1987.

Hernandez, G., and R.G. Roble, Observations of large scale thermospheric waves during geomagnetic storms, J. Geophys. Res., 83, A12, 5531-5538, 1978.

Hernandez, G., and R. G. Roble, The geomagnetic quiet nighttime thermospheric wind pattern over fritz peak observatory during solar cycle minimum and maximum, J. Geophys. Res., 89, 327337, 1984.

Holzworth, R. H. and C. -I. Meng, Auroral boundary variations and the interplanetary magnetic field, Planet. Space Sci., 32, 25 29,1984

Iijima, T., R. Fijii, T. A. Poterma, and N. A. Saflekos, Field-aligned currents in the south polar cusp and their relationship to the interplanetary magnetic field, J. Geophys. Res., 83, 5595-5603, 1978.

Kan, J. R., and S. -I. Akasofu, Dynamo process governing solar wind magnetosphere energy coupling, Planet. Space Sci., 30, 367-370, 1982.

Killeen, T. L., R. A. Heelis, P. B. Hays, N. W. Spencer, and W. B. Hanson, Neutral motions of the polar thermosphere for northward interplanetary magnetic field, Geophys. Res. Lett., 12, 159-162, 1985.

Lockwood, M., Simple M-factor algorithm for improved estimation of the basic maximum usable frequency of radio waves reflected from the ionospheric F-region, IEE Proc. 130, (4) 296 302, 1983.

Mayr, H. G., and H. Volland, Theoretical model for the latitude dependence of the thermosphric annual and semiannual variations, J. Geophys. Res., 77, 34, 6774-6790, 1972.

Meloni, A, A. Wolfe, L. J. Lanzrotti, On the relationship between interplanetary quantities and the global auroral electrojet index, J. Geophys. Res., 87, 119-127, 1982. 
Mendillo, M., and K. Schatten, Influence of solar sector boundaries on ionospheric variability, J. Geophys. Res., 88(A11) 91459153, 1983.

Murayama, T., Coupling function between solar wind parameters and geomagnetic indices, Rev. Geophys. Space Phys., 20, 623$629,1982$.

Nishida, A., Coherence of geomagnetic DP2 fluctuations with interplanetary magnetic field variations, J. Geophys. Res., 73, 5549-5559, 1968.

Park, C. G., and C. -I. Meng, After effects of isolated magnetospheric substrom activity on the mid-latitude ionosphere: localized depressions in F-layer electron densities, J. Geophys. Res., 81(25) 4571-4578, 1976.

Potapova, N. I., and B. S. Shapiro, Effect of the sector structure of the interplanetary magnetic field on the ionospheric F2 layer at middle latitudes, Geomag. Aeron., 15, 927-928, 1974.

Prölss, G. W., Seasonal variations of atmospheric- ionospheric disturbances, J. Geophys. Res., 82 (10) 1635-1640, 1977.

Prölss, G. W., Magnetic storm associated perturbations of the upper atmosphere: recent results obtained by satellite-bourne gas analysers, Rev. Geophys. Space. Phys. 18(1) 183-202, 1980.

Prölss, G. W., Storm-induced changes in the thermospheric composition at middle latitudes, Planet. space Sci., 35 (6) 807-811, 1987.

Prölss, G. W., and M. Roemer, Some properties of the polar energy source and of associated atmospheric perturbations, Adv. Space Res. 5(7) 193-202, 1985.

Prölss, G. W., L. H. Brace, H. G. Mayr, G. R. Carignan, T. L. Killeen and J. A. Klobuchar, Ionospheric storm effects at subauroral latitudes: a case study, J. Geophys. Res., 96, 12751288, 1991.

Rees, D., and T. J. Fuller-Rowell, Understanding the transport of atomic oxygen within the thermosphere using a numerical global thermosphere model, Planet. Space Sci., 36 (9) 935-948, 1988.

Reiff, P. H., and J. G. Luhmann, Solar wind control of the polar cap voltage, in Solar Wind-Magnetosphere Coupling, Eds. Y. Kamide and J. A. Slavin, Terra Scientifica, Tokyo, 1986.

Reiff, P. H., R. W. Spiro, and T. W. Hill, Dependence of polar cap potential drop on interplanetary parameters, J. Geophys. Res., 86, 7639-7648, 1981.

Rishbeth, H., F-region storms and thermospheric circulation, J. Atmos, Terr. Phys., 37, 1055-1064, 1975.

Rishbeth, H., F-region storms and thermospheric circulation, in Electromagnetic coupling in the polar clefts and caps, Eds. P.E. Sandholt and A. Egeland, pp.393-406, Kluwer, Dordrecht 1989.

Rishbeth, H., T. J. Fuller-Rowell, and A. S. Rodger, F-layer storms and thermospheric composition, Phys. Scripta, 36, 327-356, 1987.

Rishbeth, H., G. L. Wrenn, and A. P. van Eyken, Antarctic special topic pp. 9-21, 1989.
Rostoker, G., and K. -G Fälthammer, Relationship between changes in the interplanetary magnetic field and variations in the magnetic field at the Earth's surface, J. Geophys. Res., 72, 5853-5863, 1967.

Russell, C. T., and R. L. McPherron, The magnetotail and substorms, Space Sci. Rev., 15, 205-266, 1973.

Samson, J. C., and K. L. Young, Some generalisations on the method of superposed epoch analysis, Planet. Space Sci., 34 (11) 1133-1142, 1986.

Schatten, K. H., and J. W. Wilcox, Response of geomagnetic activity index $K_{p}$ to interplanetary magnetic field, J. Geophys. Res., 72, 5185-5191, 1967.

Scurry, L., and C. T. Russell, Proxy studies of energy transfer to the magnetosphere, J. Geophys. Res., 96, 9541-9548, 1991.

Scurry, L., C. T. Russell, and J. T. Gosling, A statistical study of accelerated flow events at the dayside magnetopause, J. Geophys. Res., 99, 14,815-14,829, 1994.

Seaton, M. J., A possible explanation of the drop in F-region critical densities accompanying major ionospheric storms, J. Atmos. Terr. Phys., 8, 122-123, 1956.

Sojka, J. J., Global scale, physical models of the F-region ionosphere, Rev. Geophys., 27, 371-405, 1989.

Spiro, R. W., R. A. Heelis, and W. B. Hanson, Ion convection and the formulation of the mid-latitude F-region ionization trough, J. Geophys. Res. 83, 4255-4264, 1978

Triskova, L., $f_{\mathrm{o}} F 2$ response to IMF sector boundary crossings, J. Geophys.53, 68-71, 1983.

Vasyliunas, V. M., J. R. Kan, G. L. Siscoe, and S.-I. Ajkasofu, Scaling relations governing magnetospheric energy transfer, Planet. Space Sci., 30, 359-365, 1982.

Weiss, L. A., P. H. Reiff, J. J. Moses, R. A. Heelis, and B. D. Moore, Energy dissipation in substorms, in Substorms 1, Proc. Ist Int. Conf. On substorms, ESA SP-335, pp 309-318, Eur. Space Agency Publishers, ESTEC, Noordwijk, The Netherlands, 1992.

Wilkinson, P. J., Predictability of ionospheric variations for quiet and disturbed conditions, J. Atmos. Terr. Phys., 57, 1469-1481, 1995.

Wrenn, G. L., A. S. Rodger, and H. Rishbeth, Geomagnetic storms in the Antarctic F-region. 1. Diurnal and seasonal parameters for the main phase, J. Atmos. Terr. Phys., 49, 901-914, 1987.

Wu, J., and P. J. Wilkinson, Time-weighted magnetic indices as predictors of ionospheric behaviour, J. Atmos. Terr. Phys., 57, 1763-1770, 1995.

Wygant, J. R., R. B. Torbert, and F. S. Mozer, Comparison of S32 polar cap potential drops with the interplanetary magnetic field and models of magnetopause reconnection, J. Geophys. Res., 88, 5727-5735, 1983.

Zevakina, R. A., and E. V. Lavrova, Solar-terrestrial predictions Proc., 4, C27-C36, National Oceanic and Atmospheric Admin, Boulder, Colo., 1980. 